\title{
Testing the influence of habituation on genetic structure of brown bear (Ursus arctos)
}

\author{
A. Cotovelea, O. Ionescu, N. Șofletea, G. Ionescu, R. Jurj, G. Sîrbu, M. Popa, \\ M. Fedorca, C. Mariș, A.L. Curtu
}

Cotovelea A., Ionescu O., Șofletea N., Ionescu G., Jurj R., Sîrbu G., Popa M., Fedorca M., Mariș C., Curtu A.L., 2015. Testing the influence of habituation on genetic structure of brown bear (Ursus arctos). Ann. For. Res. 58(1): 81-90.

Abstract. Adult bear individuals live solitary and have prolonged parent-offspring relationships, therefore the share of learned skills compared to the inherited ones is much larger than in other carnivores. This promotes acquisition of deviated behavior and simultaneously establishment of a kinship structure. However, deviated bear behavior and human food conditioning are the symptoms of habituation. The aim of this paper is to test the genetic structuring of habituated and non-habituated individuals located in the central region of Romania (Braşov and Prahova districts), a hotspot in terms of human-bear conflicts. Seven microsatellites were used to genotype 145 samples (ear clips and tissue), out of which 82 were classified as habituated and 63 as wild individuals, respectively. Our results suggest the presence of kinship structures in habituated bear group and a reduction of genetic diversity $\left(H_{e}=0.75\right)$, while the group located in the wild registered a higher genetic diversity $\left(H_{e}=0.78\right)$ and more private alleles. The genetic differentiation suggested by the Neighbor joining cluster analysis has been strengthened by the two percent (AMOVA) differences between the two groups and highlights the negative impact of brown bear kinship structure, caused by the human expansion on wilderness. The genetic analyses indicated that the two groups share genetic variants due to the dispersal and breeding patterns of male adult bears. The emergence of genetic differences between the two groups can be avoided by preventing bears to become human-food conditioned; over time, kinship structure can pose a threat to genetic diversity. Keywords genetic structure, brown bear, habituation, management, conservation.

Authors. Ancuța Cotovelea (ancutacotovelea@yahoo.com), Ovidiu Ionescu, Mihai Fedorca, Georgeta Ionescu - Department of Forest Sciences, Transilvania University of Braşov, Forest Research and Management Institute (ICAS), Romania; Neculae Şofletea, Alexandru Lucian Curtu - Department of Forest Sciences, Transilvania University of Braşov, Romania; Ramon Jurj, George Sîrbu, Marius Popa - Forest Research and Management Institute (ICAS), Romania; Cosmin Mariş - University of Agricultural Sciences and Veterinary Medicine, Calea Aradului 119, 300645 Timişoara, Romania.

Manuscript received September 24, 2014; revised March 10, 2015; accepted March 20, 2015; online first March 25, 2015. 


\section{Introduction}

Demographic human population explosion has led to major pressures on environment, reflected also in reduction of forest habitats for large carnivores. Consequently, brown bear natural habitats have been fragmented (Swenson et al. 2000). However, the evolution of society has caused a change in human perception of this species, such that in the nineteenth and twentieth centuries, brown bear was exterminated in large areas of North America and Europe, being the main subject of anthropogenic persecution (Zedrosser et al. 2001). Human population expansion also lead to the limitation of habitats used by bear species and even carrying campaigns for their elimination (Weber \& Rabinowitz 1996, Woodroffe 2000, Gittleman \& Gomper 2001).

If generally, the brown bear avoid areas where human activities are carried out (Mace \& Waller 1996, Jerina et al. 2003), some individuals exhibit a deviant behavior and rather prefer to meet the requirements for feeding easily (Nellemann et al. 2007). These food sources are commonly available in domestic waste, close to human settlements (Elfstrom et al. 2014). Those are considered habituated bears, showing a behavior that is not natural, unusually tolerant of human presence (Schwartz et al. 2006). In search of food sources, particularly when high densities are registered, bears are approaching to human settlements and, if the domestic waste is available the individual will prefer this type of food, which can be obtained easily without efforts (Gunther et al. 2004, Rogers 2011). Nevertheless, the presence of bears in the vicinity of human settlements is often problematic, because they can cause serious damages (Røskaft et al. 2003).

The acquisition of the dietary preferences and not only, is critical for both survival and reproduction (Shettleworth 1998). Moreover, the species that have prolonged juvenile-parent relationships and then live solitary life develop a primary opportunity for social learning
(Breck et al. 2008). Most of the skills necessary for survival, under the conditions of continuous search for what is needed and for trouble avoidance, are learnt during the first two years (sometimes they need only one year) of their life in nature, while accompanied with their mother (Gilbert 1999, Breck et al. 2008). Each bear develops its own behavioral strategy, exhibiting an individualism rarely seen in animal kingdom (Huber et al. 1994). The only common component may be the opportunistic behavior; a bear quickly learns to go for an easier way whenever possible. In natural situation this optimizes the use of potential benefits of each situation. When this concerns the relation to man, the opportunistic behavior is typically not a safe way of life. It is for instance much easier for a bear to eat large quantities of food at a garbage dump, than to search for the same amount over many kilometers (Huber et al. 2005).

Aumiller \& Matt (1994) argued that brown bears could transmit human tolerance by observational learning from mother to offspring, by social or cultural transmission. Similarly, young bears may become food conditioned through their mother's behavior (Katajisto et al. 2007, Madison 2008). However, Breck et al. (2008) found no evidence of transmission of food-conditioning behavior in the related lineages of black bears. The study of the social behaviors evolution depends critically on knowing the genetic relatedness between interacting individuals (Queller \& Goodnight 1989). In a previous study, Hopkins (2013) suggested that mother-offspring social learning is the primary mechanism responsible for black bears foraging on human food in Yosemite. In addition, results also suggest that some bears are innovators, learning to forage on human food as independents. Eventually, he found no support for the genetic inheritance hypothesis.

To date microsatellites markers have been used for gaining information about the level of genetic diversity, population structuring, spatial-genetic clustering, parentage, and move- 
ments of brown bear individuals (see Cotovelea et al. 2013a for references). Higher values of expected $\left(H_{e}\right)$ /observed heterozygosity $\left(H_{o}\right)$ and a high number of private alleles occurred in the largest brown bear populations compared to the smallest ones (Swenson et al. 2011). Thus, a higher genetic diversity resulted for Romanian brown bear population (one of the largest population of Europe) when genetic parameters were considered (Cotovelea 2014a). Other techniques for assessing genetic variation consists in determining the Fixation Index (F-Inbreeding Coefficient) which is a measure of the degree of consanguinity between two individuals and expresses the expected percentage of homozygosity arising from a given system of breeding and the Analysis of Molecular Variance (AMOVA) which is an important statistical procedure that allows the hierarchical partitioning of genetic variation among populations (Peakall \& Smouse 2006).

During the last two decades, habituated bears have caused incidents in Romania and were relocated from the proximity of different cities. However, even if mothers transmit the deviated feeding behaviour to their offspring primarily via social learning or genetic inheritance, managers should concentrate their management programs on preventing females and their cubs from entering in developed areas, by ensuring natural food resources in the wild (Smith et al. 2005).

In this study we analyzed 145 individuals of brown bear, using seven nuclear DNA regions. Some individuals have originated from wilderness, while others are habituated bears, translocated from Central Romania: Braşov, Azuga, Predeal, Sinaia and Buşteni. The study aimed at assessing genetic diversity, determining cluster grouping and structuring of habituated vs. non-habituated bears. This information will contribute to a better understanding of the effects of bear's habituation on long periods as a direct consequence of deviated feeding behavior transmission and crosses between kindred individuals.

\section{Materials and methods}

\section{Study site and sampling}

All samples originate from Braşov and Prahova districts, located in the central region of Romania. The samples were classified in two hypothetical groups: habituated and non-habituated bears (Table 1). Samples from habituated bears (82 individuals) have been collected during translocation procedures (Wildlife Department/ICAS) while samples from non-habituated bears ( 63 individuals) have been collected during three different hunting seasons (2011 to 2014, under the incidence of three derogations), consequently, samples were stored in $95 \%$ ethanol (15 $\mathrm{ml}$ tubes).

\section{Genetic analyses}

DNA was extracted from a total of 145 brown bear samples, using Macherey-Nagel extraction kit (Cotovelea et al. 2013a), following the standard tissue protocol (Macherey-Nagel 2010). Seven polymorphic nuclear markers were used to amplify regions of bear genome. Microsatellites were labeled using three dyes (CY5, CY5.5 and D2) and were divided into three multiplex reactions: multiplex I (Mu50, Mu59), multiplex II (G1A, Mu51), multiplex

Table 1 Origin, gender, and age class splitting of the analyzed individuals

\begin{tabular}{lllllll}
\hline \multirow{2}{*}{ Group } & \multirow{2}{*}{ Total } & Adults & \multicolumn{3}{l}{ Sub adults } \\
\cline { 2 - 6 } & & Females & Males & Females & Cubs & Males \\
\hline Non-habituated & 63 & 20 & 10 & 18 & - & 15 \\
Habituated & 82 & 20 & 8 & 26 & 12 & 16 \\
\hline
\end{tabular}


III (G10J, G10M) and a singleplex (G10D). Loci were previously described by Paetkau et al. 1995, Taberlet et al. 1997, Paetkau et al. 1998, Bellemain \& Taberlet 2004. PCR reactions were performed in $15 \mu 1$ mixture, containing 7.5 $\mu$ l of Qiagen Multiplex PCR Kit, $2 \mu l$ of DNA and fluorescently labeled markers (concentration depending on marker). Fragment analysis was performed in a mixture of $40 \mu 1$ consisting of SLS, Size Standard and PCR product, using the FRAG-3 method on the GenomeLab $^{\text {TM }}$ GeXP Genetic Analysis System. Alleles were scored using GenomeLab ${ }^{\mathrm{TM}}$ Software (Beckman Coulter, Inc).

\section{Data analysis}

Observed $\left(H_{o}\right)$ and expected heterozygosities $\left(H_{e}\right)$, Fixation Index ( $F$-inbreeding coefficient), number of different allels $(A)$; number of effective alleles $\left(A_{e}\right)$ were calculated for each locus in GenAlEx v. 6.5 (Peakall \& Smouse 2006), likewise Principal Coordinates (PCoA) analysis and AMOVA were generated using the same software for testing individuals grouping (habituated vs. non-habituated). In addition, statistical tests: Tukey, NewmanKeuls' and Duncan's (XLSTAT software) were run in order to check for statistical differences between the heterozigosity mean values of the two groups. KINGROUP software was used (Konovalov et al. 2004) to determine groups of kin that share a common relationship by estimating an overall likelihood for alternative partitions. Statistical significance was assessed by $P$-values using a Bonferroni correction for multiple tests (Hochberg 1988).

We used a clustering method for inferring population structure in STRUCTURE v. 2.3.4 (Pritchard et al. 2000, Falush et al. 2003, 2007, Hubisz et al. 2009) based on Markov Chain Monte Carlo (MCMC) method. Model admixture was employed and has been set for 100000 replicates followed by 50000 burn-in length, in order to determine the most likely number of clusters of individuals $(K)$. Values for $K$ varied from one to five ensuring five repetitions for 84 each $K$. Both the posterior probability of the data for the given value of $\mathrm{K}(\operatorname{Ln} \operatorname{Pr}(X \mid K))$ and its rate of change $(\Delta K)$ were used in detecting groups (Evanno et al. 2005). The Population v. 1.2.3.2 software (Langella 1999) was used to calculate the Cavalli-Sforza (1967) genetic distance, utilizing Neighbor joining clustering algorithm (500 bootstraps), and the software TreeView (Roderic 2000) for viewing phylogenetic tree. Furthermore, we calculated genetic distance considering four groups: habituated bears from Braşov (HabBV), habituated bears from Prahova $(\mathrm{HabPH})$, non-habituated individuals from Brasov (Non-habBV) and nonhabituated bears from Prahova (Non-habPH).

\section{Results}

A comparative analysis of habituated and non-habituated bears (Table 2) indicated the presence of a high genetic diversity for both groups $\left(H_{e}=0.78\right.$ and $\left.H_{e}=0.75\right)$. Habituated bears group has registered a slightly lower value for both expected and observed heterozigosity than the non-habituated group (Table 2). However, the differences between the two groups were not statistically significant $(p>$ $0.05)$ and has resulted after applying all three tests. However, some deviations have been registered for the number of effective alleles, non-habituated individuals recorded a slighly higher number $\left(N_{e}=4.90\right)$ than the habituated ones (Table 2). A negative value of the fixation index $(F)$ have been registered, indicating an excess of heterozygous, due to negative assortative mating in both groups; for non-habituated individuals the value was slightly further from zero indicating the presence of an excess of heterozygous (Table 2).

Mean $F_{S T}$ value of 0.01 , based on the variance of alleles frequencies between groups, has indicated small differences among habituated and non-habituated individuals at the seven analyzed markers (data not shown). Using the observed allele frequency distribution, we randomly generated 1000 pairs of unrelated 
Table 2 Comparative values of genetic parameters for habituated bears and wild bears

\begin{tabular}{llrrrrrr}
\hline Groups & Locus & $\mathrm{N}$ & \multicolumn{1}{c}{$A$} & $A_{e}$ & $H_{o}$ & $H_{e}$ & $F$ \\
\hline Habituated & G10J & 82 & 9 & 3.70 & 0.77 & 0.73 & -0.05 \\
& MU50 & 82 & 12 & 4.75 & 0.73 & 0.79 & 0.07 \\
& MU59 & 82 & 15 & 6.81 & 0.81 & 0.85 & 0.06 \\
& MU51 & 82 & 7 & 4.22 & 0.81 & 0.76 & -0.06 \\
& G10D & 82 & 6 & 4.45 & 0.83 & 0.78 & -0.07 \\
& G1A & 82 & 7 & 4.45 & 0.88 & 0.78 & -0.13 \\
Non-habituated & G10M & 82 & 6 & 2.61 & 0.76 & 0.62 & -0.23 \\
& G10J & 63 & 12 & 3.02 & 0.76 & 0.67 & -0.14 \\
& MU50 & 63 & 11 & 5.56 & 0.83 & 0.82 & -0.01 \\
& MU59 & 63 & 15 & 8.78 & 0.94 & 0.89 & -0.06 \\
& MU51 & 63 & 8 & 4.73 & 0.84 & 0.79 & -0.07 \\
& G10D & 63 & 6 & 4.07 & 0.84 & 0.75 & -0.12 \\
\hline Habituated & G1A & 63 & 7 & 5.02 & 0.87 & 0.80 & -0.09 \\
\hline Non-habituated & G10M & 63 & 6 & 3.11 & 0.76 & 0.68 & -0.12 \\
\hline
\end{tabular}

Note. Abbreviations: $\mathrm{N}$ - number of individuals, $A$ - number of different alleles, $A_{e}$ - number of effective alleles, $H_{o}$ observed heterozygosity, $H_{e}$ - expected heterozygosity, $F$ - fixation index.

individuals, 1000 pairs of siblings and 1000 pairs of full siblings. An unbiased method for estimating the true relatedness between individuals was used, and the results indicated the highest number of related individuals in habituated bears group $(p<0.1 \%)$ (data not shown).

The number of private alleles calculated for the non-habituated bears vs. habituated bears (Figure 1), registered a higher value for the first group (11), respectively a higher frequency corresponding to the same group (4\%). Private alleles appearance is correlated with the migrant's number per generation between groups and indicates the ongoing gene flow. Thus, non-habituated individuals group records a panmitic structure, while kinship structuring of habituated bears can lead to negative effects arising inbreeding.

Two percent differentiation in molecular variance between the two groups was registered after applying AMOVA test; the differences are small and somewhat anticipated, if we consider the large distances which are being used by brown bears for movements. Therefore we conclude that might have captured the influence of related bears lineages. Hence, the higher genetic differences are found inside groups.

Bayesian clustering analysis indicated the presence of four groups, when $\Delta K$ analysis was performed (Evanno et al. 2005). However, this result was considered ambiguous due to analysis of the mean of estimated Ln probability of data (data not shown) indicated the presence of one group. This result can be caused by the strong kinship structure of the habituated individuals. Individual family grouping of habituated bears from Braşov, respectively Prahova, can determine the occurrence of the four groups (Figure 2). A priori analysis of the Bayesian histogram has indicated the uncertainty of the $\Delta K$ analysis (data not shown); the genetic clusters have not shown a clear differentiation, each group indicating a mixture of 

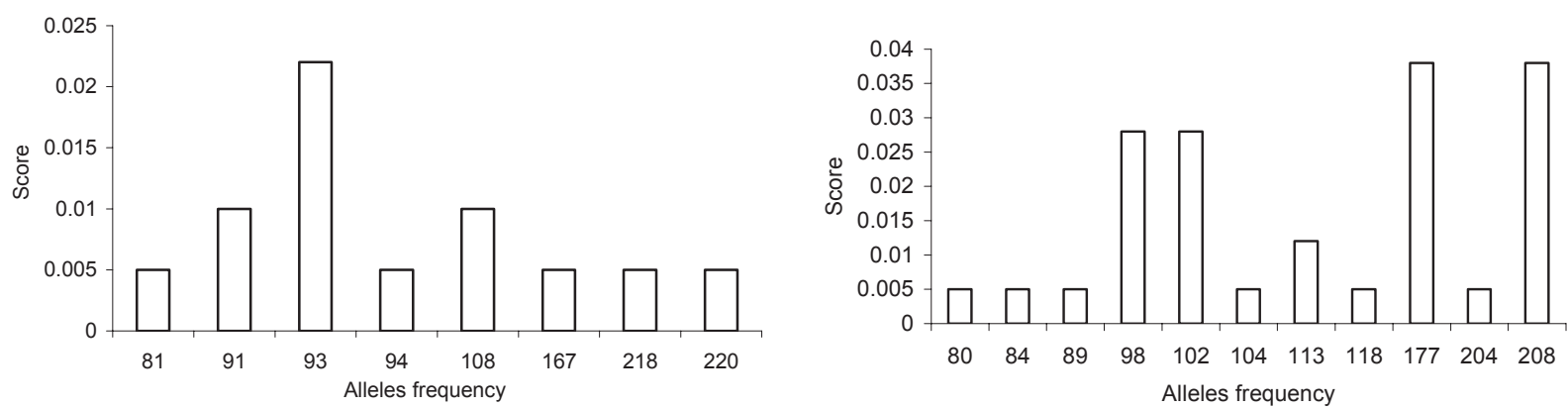

Figure 1 Private alleles frequency for wild bears (non-habituated) (left) and habituated bears (right)

Axis significance: on $\mathrm{X}$ is the allele length in base pairs (bp) and on $\mathrm{Y}$ the allele frequency. In non-habituated bears, the allele 177 registered the highest frequency (0.04) and the total number of private alleles is 11 , while in habituated bears the allele 93 registered the highest frequency $(0.02)$ and the total number of private alleles is 8 .
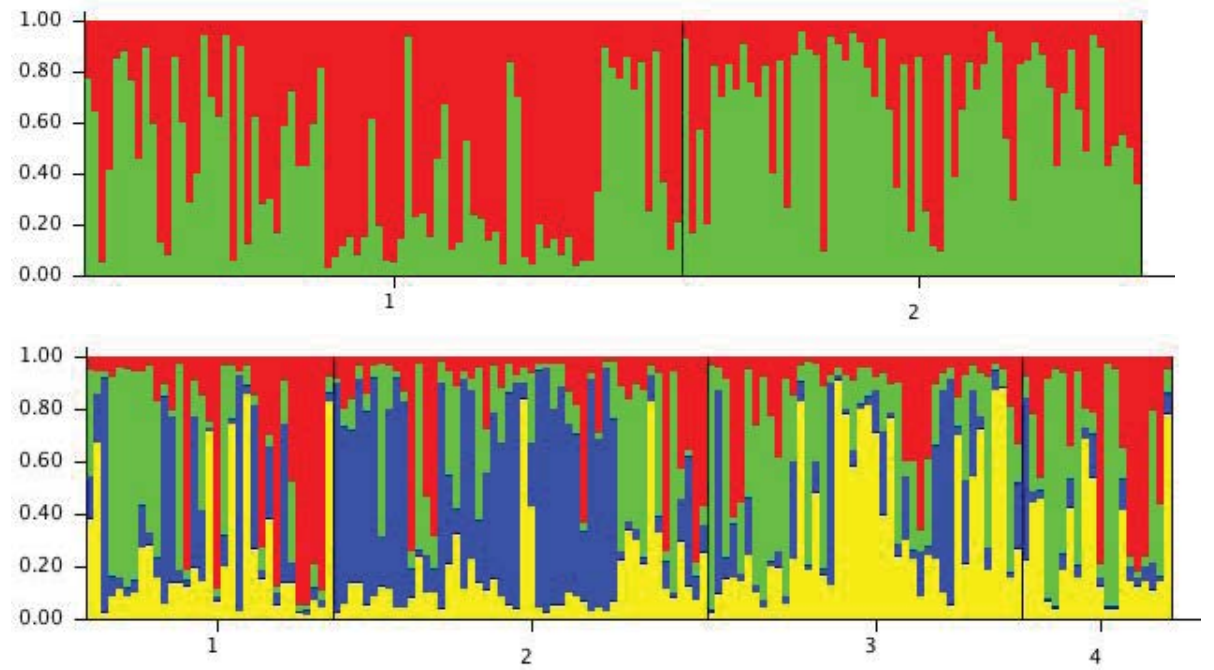

Figure 2 Histogram resulted from Bayesian analysis for habituated vs wild individuals

$K=2$; Number 1 represents habituated bears group, while number 2 is the wild bears group. Each bar represents an individual. The two green and red colors represent cluster number $(K=2)$ highlighting the likelihood probability of belonging to first or to the second cluster. b) $K=4$; Number 1 represents HabBV, 2 - HabPH, 3 - Non-habBV, 4 - NonhabPH. Each bar represents an individual. The four green, red, blue and yellow colors represent cluster number $(K=4)$, highlighting the likelihood probability of belonging to one of the four clusters.

bear individuals belonging to the groups (Figure 2).

Results indicated the presence of three clusters, with a high bootstrap support of $77 \%$. First cluster consisted in the two habituated groups, thus indicating the gene flow presence between them, while second and third clus- ter consisted in Non-habBV and Non-habPH (Figure 3).

When the unbiased method for estimating the true relatedness between individuals was used (we randomly generated 1000 pairs of unrelated individuals, 1000 pairs of siblings and 1000 pairs of full siblings), we have found 


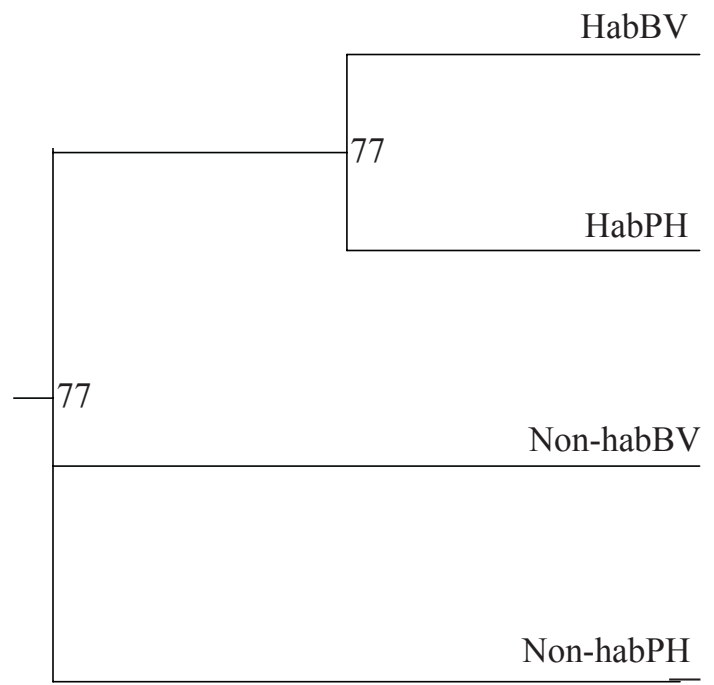

Figure 3 Neighbor joining dendrogram (TreeView) for the four groups based on Cavalli-Sforza genetic distance

The four groups are divided in three clusters: Non-habPH (non-habituated individuals from Prahova) and NonhabBV (non-habituated bears from Braşov) as two separated clusters and the two habituated groups from Braşov and Prahova (77\% bootstrap support) which are been grouped in one cluster.

the highest number of related individuals in habituated bears from Prahova $(p<0.1 \% ; 50)$, followed by habituated individuals from Brasov $(p<0.1 \% ; 16)$. Wild individuals from both regions $(p<0.1 \%$; $\mathrm{Ph}: 7 ; \mathrm{Bv}: 10)$ registered lower values (data not shown).

The genetic parameters generated for the four groups indicated a high value of genetic diversity for all analyzed groups: Non-habBV $\left(H_{e}=0.77\right)$, HabBV $\left(H_{e}=0.75\right)$, Non-habPH $\left(H_{e}=0.74\right)$ and HabPH $\left(H_{e}=0.74\right)$, respectively (data not shown). However, the results obtained for the group Non-habPH should be interpreted with caution, due to the smaller number of samples by comparison with the others.

The differences between the four groups did not receive support via $\mathrm{PCoA}$ analysis while AMOVA test indicated the presence of a lower percentage $(3 \%)$ differences in molecular variance between the four groups (data not shown). Even so, the higher differences regarding the genetic structuring, are found within the groups (data not shown). Overall, the results indicated no clear differentiation between the four populations, ultimately an unsurpris- ingly result, if we consider the bear ethology (a large mammal which moves on long distances).

\section{Discussion}

The level of genetic diversity observed in this study (if we consider the two groups) is lower than reported in previous studies for Romanian brown bear population $\left(H_{e}=0.80\right)$ (Cotovelea 2014a). However, the comparison should be treated with caution, due to the lower number of microsatellites analyzed in this study. The number of different alleles is smaller likewise from those obtained by Cotovelea (2014a), but similar with those obtained by Zachos et al. (2008), where a similar set of markers were analyzed.

Results of the first analysis, when two groups were considered, indicated a higher value for genetic diversity and private alleles numbers of the wild bears group, while the analysis of fixation index revealed a slightly higher value for genetic inbreeding in habituated bears. Nevertheless our results indicate the presence 
of gene flow between the two groups; differences between the values of genetic parameters are likely to occur due to the presence of kinship structure in habituated bears group.

Genetic differentiation of habituated group of bears, which seems to present a kinship structure, emerges in the fact that these individuals are predominantly mothers and their offspring, who have acquired additional behavior of feeding on waste deposited at the periphery of localities: Braşov, Buşteni, Sinaia, Azuga and Predeal. However, this division into the two groups showed no statistical support, when the mean of estimated Ln probability of data and Bayesian histogram have been analyzed. Ultimately the hypothesis of dividing individuals in two distinct genetic clusters was rejected. This result has received no support when the mean values of the heterozygosity of the two groups were tested. The mean number of different alleles was equal for both groups, the differences appears when we consider the number of effective alleles, thus a higher value has been registered by the bears from wilderness.

On the other hand, Neighbor joining analysis implemented for the four groups indicated a clear separation in three clusters: one cluster represented by the habituated bears and the other two by the wild ones. We consider that the presence of such separation is determined by the number of private alleles and by the kinship structure of habituated bears. We need to highlight the presence in the same cluster of both habituated groups thus confirming the gene flow ongoing between them and similarities between related lineages. Two clusters grouping of the wild individuals (Braşov and Prahova) can raise a question about the absence of interbreeding with habituated bears, samples being located on the opposite sides of the national road (DN1) can suggest a gene flow discontinuity. In a subsequent research, we are going to consider a gene flow simulation between individuals, in order to test the landscape resistance on brown bear movements in the area (Cotovelea 2014b). Even if AMOVA 88 test indicated the presence of tree percent of genetic differences between the four groups, result did not correspond with PCoA analysis, where no separation between the four groups was revealed. Likewise hypothesis of separating the four groups did not receive support from the Bayesian analysis.

Only several reports have addressed to comparison between habituated bears and wild (non-habituated) individuals (Breck et al. 2008, Madison 2008, Hopkins 2013). It should be noted that Romanian population records one of the highest value for brown bear densities (Ionescu 1999, Jerina et al. 2013), which can often lead to the appearance of deviated behavior (Elfstrom et al. 2014). Therefore the number of habituated bears in the past ten to twenty years registered an increasing trend, following the trend of increasing population size on national level (Cazacu et al. 2014).

\section{Conclusions}

The lack of sub structuring of habituated and non-habituated bear groups based on model clustering indicated the presence of gene flow via male bears dispersing from wilderness, maintain thus genetic diversity, and remain devoid of problems associated with genetic isolation and inbreeding. This genetic information exchange can be ensured only if the groups are not isolated and is mainly correlated with landscape resistance to bear's movements.

Neighbor joining analysis of the four groups indicated a clear separation in three branches, however the presence of such separation is determined by the number of private alleles and the kinship structure of habituated bears. The emergence of genetic differences between the groups (non-habituated and habituated) can be avoided by preventing bears to become humanfood conditioned, over time kinship structure representing a threat to gene diversity. Habituated bears groups are reliant on periodic gene flow, thus via species management, male bears dispersing from wilderness should be ensured, 
thereby maintaining genetic diversity, and preventing the appearance of problems associated with inbreeding.

\section{Acknowledgements}

This paper is supported by the Sectoral Operational Programme Human Resources Development (SOP HRD), ID134378 financed from the European Social Fund and by the Romanian Government. This study has received funding from the project PN09460210 (ANCS) and samples were collected under the derogations of Ministry of Environment and Climate Change. We are particularly grateful to the hunting administrators for collecting tissue samples and to other colleagues from ICAS. We are thankful to the International Council for Game and Wildlife Conservation (CIC)/Working Group Young Opinion for the research funding grant for young scientists.

\section{References}

Aumiller L.D., Matt C.A., 1994. Management of McNeil River State Game Sanctuary for viewing of brown bears. International Conference on Bear Research and Management 9: 51-61.

Bellemain E., Taberlet P., 2004. Improved noninvasive genotyping method: application to brown bear (Ursus arctos) faeces. Molecular Ecology Notes 4: 519-522. DOI: 10.1111/j.1471-8286.2004.00711.x.

Breck S.W., Williams C.L., Beckmann J.P., Matthews S.M., Lackey C.W., Beecham J.J, 2008. Using genetic relatedness to investigate the development of conflict behavior in black bears. Journal of Mammalogy 89: 428-434. DOI: 10.1644/07-MAMM-A-028R2.1.

Cazacu C., Adamescu M.C., Ionescu O., Ionescu, G., Jurj R., Popa M., Cazacu R., Cotovelea A., 2014. Mapping trends of large and medium size carnivores of conservation interest in Romania. Annals of Forest Research 57: 97-107.

Cotovelea A., 2014a. Assessing the genetic structure of brown bear (Ursus arctos L.) in Romanian Carpathians using molecular markers. Ph.D. Thesis, $138 \mathrm{p}$.

Cotovelea A., 2014b. Predictive models for gene flow "landscape genetics" in Romanian large carnivores populations. Revista de Silvicultură şi Cinegetică 34.

Cotovelea A., Şofletea N., Ionescu G., Ionescu O., 2013 a. Genetic approaches for Romanian brown bear Ursus arctos. conservation. Bulletin of the Transilvania University of Braşov 6.

Cotovelea A., Şofletea N., Ionescu G., Jurj R., Ionescu O., 2013b. Dna isolation and amplification in Romanian species of wild animals. Proceeding of the Forest and Sustainable Development. Braşov, România, 19-20 October 2012.

Evanno G., Regnaut S., Goudet, J., 2005. Detecting the number of clusters of individuals using the software STRUCTURE: a simulation study. Molecular Ecology 14: 2611-2620. DOI: 10.1111/j.1365-294X.2005.02553. $\mathrm{x}$.

Elfström M., Zedrosser A., Jerina K., Støen O.G., Kindberg J., Budic L., Jonozovič M., Swenson J.E., 2014. Does despotic behavior or food search explain the occurrence of problem brown bears in Europe? The Journal of Wildlife Management. DOI: 10.1002/jwmg.727.

Falush D., Stephens M., Pritchard J.K., 2003. Inference of population structure using multilocus genotype data: Linked loci and correlated allele frequencies. Genetics 164: 1567-1587.

Falush D., Stephens M., Pritchard J.K., 2007. Inference of population structure using multilocus genotype data: dominant markers and null alleles. Molecular Ecology Notes 7: 574-578. DOI: 10.1111/ j.1471-8286.2007.01758.x.

Gilbert B.K., 1999. Opportunities for social learning in bears. Mammalian social learning: comparative and ecological perspectives. In: Box, H. O., Gibso (eds.), Cambridge University Press, Cambridge, United Kingdom.

Gittleman J.L., Gompper M.E., 2001. The risk of extinction: What you don't know will hurt you. Science 291: 997-999. DOI: 10.1126/ science.291.5506.997.

Hochberg Y., 1988. A sharper Bonferroni procedure for multiple tests of significance. Biometrika 75: 800-802 DOI: $10.1093 /$ biomet/ 75.4.800.

Gunther K.A., 2004. Management of habituated grizzly bears in North America. In: Rahm J. (ed.), Transactions of the 69th North American Wildlife and Natural Resources Conference. Washington: Wildlife Management Institute.

Hopkins J.B, 2013. Use of genetics to investigate socially learned foraging behavior in free-ranging black bears. Journal of Mammalogy 94: 1214-1222. DOI: 10.1644/13-MAMM-A-009.1.

Huber, D., Dabanovic, V., Kusak, J., Frkovic A., 1994. Reintroduction of hand-reared brown bears into the wild: experiences, problems. In: Dorrestein, G.M. Kahraman, M. (eds.) Proceedings of the International Conference on Aspects of Bear Conservation, Bursa, Turkey 179186.

Huber D., 1995. Rehabilitation and release of bears. Zoologischer Garten Köln, 163 p.

Hubisz M.J., Falush D., Stephens M., Pritchard J.K., 2009. Inferring weak population structure with the assistance of sample group information. Molecular Ecology Resources 9: 1322-1332. DOI: 10.1111/j.1755- 
0998.2009.02591.x.

Ionescu O., 1999. The management of the brown bear in Romania. Bear Conservation Action Plan, IUCN.

Jerina K., Jonozovič M., Krofel M., Skrbinšek T., 2013. Range and local population densities of brown bear Ursus arctos in Slovenia. European Journal of Wildlife Research 59: 459-467. DOI: 10.1007/s10344-0130690-2.

Jerina K., Debeljak M., Džeroski S., Kobler A., Adamič, M., 2003. Modeling the brown bear population in Slovenia. Ecological Modelling 170: 453-469. DOI: 10.1016/S0304-3800(03)00245-X.

Konovalov D.A., Manning C., Henshaw M.T., 2004. KinGroup: a program for pedigree relationship reconstruction and kin group assignments using genetic markers. Molecular Ecology Notes 4: 779-782. DOI: 10.1111/j.1471-8286.2004.00796.x.

Langella O., 1999. Populations version 1.2.30. Distributed by the author, CNRS UPR9034, France.

Mace R.D., Waller J.S., 1996. Final report: grizzly bear ecology in the Swan Mountains, Montana.

Madison J.S., 2008. Yosemite National Park: the continuous evolution of human-black bear conflict management. Human-Wildlife Conflicts 2:153-157.

Nellemann C., Støen O.G., Kindberg J., Swenson J.E., Vistnes I., Ericsson, G., Katajisto J., Kaltenborn B.P., Martin J., Ordiz A., 2007. Terrain use by an expanding brown bear population in relation to age, recreational resorts and human settlements. Biological Conservation 138: 157-165. DOI: 10.1016/j.biocon.2007.04.011.

Paetkau D., Shields G.F., Strobeck, C., 1998. Gene flow between insular, coastal and interior populations of brown bears in Alaska. Molecular Ecology 7: 12831292. DOI: 10.1046/j.1365-294x.1998.00440.x.

Paetkau D., Calvert W., Stirling I., Strobeck, C., 1995. Microsatellite analysis of population structure in Canadian polar bears. Molecular Ecology 4: 347-354. DOI: 10.1111/j.1365-294X.1995.tb00227.x.

Peakall R.O.D., Smouse P.E., 2006. Genalex 6: Genetic analysis in Excel. Population genetic software for teaching and research. Molecular Ecology Notes, 6, 288-295. DOI: 10.1111/j.1471-8286.2005.01155.x.

Pritchard J.K., Stephens M., Donnelly, P., 2000. Inference of population structure using multilocus genotype Data. genetics 155: 945-959.

Roderic D. M., 2000. TREEVIEW: An application to display phylogenetic trees on personal computers. Com- puter Applications in the Biosciences 12: 357-358.

Rogers L.L., 2011. Does diversionary feeding create nuisance bears and jeopardize public safety? Human Wildlife Interactions 5: 287-295.

Røskaft E., Bjerke T., Kaltenborn B., Linnell J.D.C., Andersen R., 2003. Patterns of self-reported fear towards large carnivores among the Norwegian public. Evolution and Human Behavior 24: 184-198. DOI: 10.1016/ S1090-5138(03)00011-4.

Schwartz C.C., Haroldson M.A., Gunther K.A., Moody D., 2006. Distribution of grizzly bears in the Greater Yellowstone Ecosystem in 2004. Ursus 17: 63-66. DOI: 10.2192/1537-6176(2006)17 [63:DOGBIT]2.0.CO;2.

Shettleworth S.J., 1988. Foraging as operant behavior and operant behavior as foraging. What have we learned? Psychology of Learning and Motivation 22: 1-49.

Smith T., Herrero S., DeBruyn T., 2005. Alaskan brown bears, humans and habituation. Ursus 16: 1-10. DOI: 10.2192/1537-6176(2005)016[0001: ABBHAH]2.0.CO;2.

Swenson J.E., Gerstl N., Dahle B., Zedrosser A., 2000. Action Plan for the conservation of the Brown Bear Ursus arctos in Europe.

Swenson J.E. Taberlet, P., Bellemain, E. 2011. Genetics and conservation of European brown bears Ursus arctos. Mammalian Revue 41: 87-98. DOI: 10.1111/ j.1365-2907.2010.00179.x.

Queller D.C., Goodnight K.F., 1989. Estimating relatedness using molecular markers. Evolution 43: 258-275. DOI: $10.2307 / 2409206$.

Zachos F.E., Otto M., Unici R., Lorenzini R., Hartl G.B., 2008. Evidence of a phylogeographic break in the Romanian brown bear Ursus arctos, population from the Carpathians. Mammalian Biology - Zeitschrift für Säugetierkunde 73: 93-101.

Zedrosser A., Dahle B., Swenson J.E., Gerstl N., 2001. Status and management of the brown bear in Europe. Ursus 12: 9-20.

Weber W., Rabinowitz A.R., 1996. A global perspective on large carnivore conservation. Conservation Biology 10: 1046-1054. DOI: 10.1046/j.1523-1739.1996.10041046. $\mathrm{x}$.

Woodroffe R., 2000. Predators and people: using human density to interpret declines of large carnivores. Animal Conservation 3: 165-173. DOI: 10.1111/j.14691795.2000.tb00241.x. 